\title{
The prognostic impact of Wilms tumor-1 polymorphism (rs16754) and human myeloid inhibitory C-type lectin-like receptor expression in cytogenetically normal-acute myeloid leukemia
}

\author{
Hanan M. Bedair ${ }^{1}$, Mohamed H. Attia ${ }^{2}$, Suzy F. Gohar ${ }^{3,4^{*}}$ (D), Fatma M. Khalaf ${ }^{5}$, Sahar Badr El-DIN ${ }^{6}$ and Hatem Rabie ${ }^{1}$
}

\begin{abstract}
Background: There are several genetic mutations that carry prognostic and predictive values in acute myeloid leukemia (AML). They are also implicated in disease pathogenesis and patient outcome. They can be a target of novel therapies for AML. The aim of the current study was to investigate prognostic value of Wilms' tumor-1 (WT1) genotypes and human myeloid inhibitory C-type lectin-like (hMICL) receptor expression in normal-cytogenetic group of patients with AML. Genotyping of WT1 mutations was done by Rotor Gene real-time polymerase chain reaction (PCR) while hMICL expression was detected using phycoerythrin (PE)-conjugated mouse monoclonal antihuman (MoAbs) by flow cytometry.

Results: Sixty-three patients with cytogenetically normal AML (CN-AML) were included in the study. The alternate allele of WT1 single nucleotide polymorphism (SNP) rs 16754 was found in 26.89\%. At day 28 of therapy, complete remission was achieved in 100\% of cases harboring mutant AG plus GG genotypes but only in $6.38 \%$ of cases harboring wild genotype (AA). After 6 months, $88.23 \%$ of patients harboring WT1 mutant genotype maintained complete remission, while only $23.40 \%$ of patients with wild type showed complete remission. The overall survival in patients harboring mutant WT1 genotypes was significantly longer than in those who carried the wild type gene (Pvalue, 0.001 ). Additionally, hMICL was overexpressed in approximately $87.3 \%$ of AML cases and inversely related to complete response. Similarly, overall survival was significantly shorter in patients with positive hMICL (P-value, 0.001). Conclusion: Mutant WT1 genotypes (SNP rs16754) were conversely, associated with complete response, and hMICL overexpression had poor prognostic value in AML.
\end{abstract}

Keywords: Acute leukemia, Myeloid neoplasm, Cytogenetic, Genotypes, Prognosis, Wilms' tumor

\footnotetext{
* Correspondence: sozy.johar@med.menofia.edu.eg

${ }^{3}$ Clinical Oncology Department, Faculty of Medicine, Menoufia University, A Minufiyah 32511, Egypt

${ }^{4}$ shibin elkom, Egypt

Full list of author information is available at the end of the article
}

\section{Springer Open}

(c) The Author(s). 2021 Open Access This article is licensed under a Creative Commons Attribution 4.0 International License, which permits use, sharing, adaptation, distribution and reproduction in any medium or format, as long as you give appropriate credit to the original author(s) and the source, provide a link to the Creative Commons licence, and indicate if changes were made. The images or other third party material in this article are included in the article's Creative Commons licence, unless indicated otherwise in a credit line to the material. If material is not included in the article's Creative Commons licence and your intended use is not permitted by statutory regulation or exceeds the permitted use, you will need to obtain permission directly from the copyright holder. To view a copy of this licence, visit http://creativecommons.org/licenses/by/4.0/. 


\section{Background}

Acute myeloid leukemia (AML) is a heterogeneous disease in clinical presentation. Its biological behavior characterized by cytogenetic abnormalities, which provide powerful prognostic information [1].

Many curatively treated patients with AML have relapse but estimated to be in complete remission (CR) by standard diagnostic criteria [2]. This is thought to be caused by the presence and outgrowth of sustaining leukemic stem cells in the bone marrow (BM), termed minimal residual disease (MRD) [3].

Cytogenetically normal AML (CN-AML) represents the largest cytogenetic group of AML cases [4]. Better understanding of the pattern of gene mutation in this group of patients will improve diagnostic, prognostic, and therapeutic options for MRD [5]. Additionally, formal proof supporting preventive intervention of patients with MRD-positive AML is still limited [6, 7].

The Wilms' tumor 1 (WT1) gene is a tumor suppressor gene located on chromosome $11 \mathrm{p} 13$ and has a regulatory role in normal and malignant hematopoiesis [8]. WT1 is expressed in CD34-positive progenitor cells and is downregulated during the process of hematopoietic differentiation and undetectable in mature leukocytes [9].

The most important WT1 gene mutations associated with AML are clustered in exon 7 (hotspot region), and single nucleotide polymorphism (SNP), rs16754, is also located in this region [10]. This gene mutation was reported in approximately $10 \%$ of patients with CN-AML [1].

WT1 gene overexpression could be observed in many patients with AML at diagnosis, which disappeared when CR was achieved by chemotherapy [11]. Hence, WT1 gene expression has been regarded as a potential biomarker for the detection of MRD in AML, and disappearance of WT1 gene positivity during chemotherapy had a favorable effect on survival $[12,13]$.

The human myeloid inhibitory C-type lectin-like receptor (hMICL) (also known as CLL-1, KLR1, and CLEC12A) is present on monocytes and granulocytes in normal peripheral blood and BM. The function of this heavily glycosylated trans-membrane C-type lectin not well established. However, there is some evidence that hMICL is involved in the control of myeloid cell activation during inflammation [14]. It has been reported that hMICL is a marker for LSCs and is a possible target in antibody-mediated anti-leukemia treatment [15].

Based on these data, our study aimed to assess the prevalence of WT1 SNP rs16754 and hMICL expression and to determine the prognostic significance of both genes in cytogenetically normal adult patients with AML.

\section{Methods}

This study included 63 patients with CN-AML. Blood samples of patients were collected in the clinical oncology department Menoufia University and haematooncology units of Ain Shams University Hospitals and examined in the clinical pathology department of the National Liver Institute, Menoufia University. The diagnosis and classification of AML were based on morphologic and cytochemical evaluation, immunophenotyping (IPT), and cytogenetic study according to the 2016 World Health Organization criteria for classification of tumors of hematopoietic and lymphoid tissues [16].

Patients with poor performance status, significant comorbidities, acute promyelocytic leukemia (M3 subtype), biphenotypic leukemia, therapy-related AML, acute lymphoblastic leukemia (ALL), myelodysplastic syndrome (MDS), other hematologic diseases, and solid tumor malignancy were excluded because of the difference in their pathogenesis and survival rate in relation to other types of AML.

Either verbal or written consents were obtained from all subjects before their enrollment in the study, and conventional data were collected from the patients' medical records. The study protocol was in accordance with the Declaration of Helsinki and approved by the Scientific and Ethical Committee of National Liver InstituteMenoufia University.

All studied patients were subjected to full history taking and clinical examination stressing on fever, bleeding tendency, easy fatigability, bone pain, pallor, purpuric eruptions, hepatomegaly, splenomegaly, lymphadenopathy, and central nervous system involvement.

Imaging studies included chest and abdominal computed tomography (CT) or chest radiography and abdominal ultrasonography. Brain CT without contrast was performed when central nervous system (CNS) hemorrhage was suspected, while brain magnetic resonance imaging was performed when leukemic meningitis was suspected, and lumbar puncture was indicated (to assess CNS involvement or exclude meningitis). Assessments of cardiac risk markers and myocardial function (by echocardiogram) were conducted as induction regimens containing anthracycline.

\section{Laboratory investigations and sampling}

a. Complete blood count was performed using Sysmex XT-1800i automated hematology analyzer (Sysmex Corporation, Kobe, Japan), and peripheral blood smear was stained by Leishman for examination.

b. Cytochemistry and morphology were performed for peripheral blood and BM myeloid and lymphoid blast cells using Giemsa stains, myeloperoxidase reaction, and nonspecific esterase using alpha-naphthyl-acetate according to the FAB classification [17].

c. Cytogenetic study was conducted on fresh BM samples or after 1-3 days of unstimulated culture. 
Metaphase chromosomes banding analysis was performed in all patients using trypsin-Giemsa method after the standard methods [18] and karyotyped in accordance with the International System for Human Cytogenetic Nomenclature [19].

a. IPT was performed on blast cells. The samples were used either fresh or left for $24 \mathrm{~h}$ at $4{ }^{\circ} \mathrm{C}$ (if fresh samples were not used for the IPT at the same day) using EPICS XL Coulter Flow Cytometer (Beckman Coulter, Hialeah, FL, USA). Monoclonal antibodies were as follows: B cell panels, CD10, CD19, CD20; T cell panel, CD2, CD5, CD7 to exclude ALL; myeloid markers, CD13, CD33, and CD14 as monocytes markers; and cytoplasmic MPO as myeloid specific marker. The nonspecific lineageantigens HLA-DR and CD34 were used to detect the phenotypes of leukemic cells. The percentage of relevant studied markers was determined on the blast cells as a percentage of the gated blast cells. The blast cells were considered positive for the marker if $>20 \%$ of cells expressed this marker; however, intracellular MPO and CD34 expression was considered positive if $>10 \%$ of cells expressed this marker as shown in the results of Kaleem et al. [19].

b. hMICL expression by flow cytometer. Its mean fluorescence intensity was performed on BM blast cells by EDTA blood sampling using flow cytometry (FCM). The used monoclonal antibody was phycoerythrin-conjugated mouse monoclonal anti-hMICL (CD123/hMICL/CD133/CD45) which was purchased from Miltenyi Biotech (Bergisch Gladbach, Germany). The vial supplied $25 \mu \mathrm{g}$ of antibody was diluted in $1 \mathrm{~mL}$ saline containing $0.5 \%$ bovine serum albumin and $0.1 \%$ sodium azide (R\&D systems, Minneapolis, USA). Negative control was used (appropriately labeled according to the MoAbs used) to assess background fluorescence intensity of nonspecific MoAbs binding. Samples were considered positive for hMICL expression if expressed by $\geq 10.5 \%$ of the gated blast cells, with the negative isotope control was approximately $2 \%$ (based on data and statistics obtained from controls, the negative isotypic control was set at $2 \%$ ).

c. Genotyping of WT1 mutations. Extraction of genomic DNA from peripheral blood or BM samples according to the manufacturer's instructions was conducted using Qiagen BioRobot M48 DNA Mini Kit (Qiagen, Hilden, Germany). The extracted DNA was stored at $-20^{\circ} \mathrm{C}$ until use for WT1 genotyping by real-time polymerase chain reaction (PCR). After this extraction and isolation, samples were tested to DNA purity and finally stored at $-80{ }^{\circ} \mathrm{C}$ until use.
After that, PCR was performed for detection of WT1 SNP (rs16754) at exons 7 by ABI TaqMan allelic discrimination kit, catalog number of 81479 (Applied Biosystems, Carlsbad, CA) using the Rotor-Gene Real-Time PCR System (QIAGEN, GmbH). The fluorescent labeled probes with the context sequence for exon 7 FAM dye for allele G: TTACTCTCTGCCTGCAGGATGTGCGA $\mathrm{C}$ and VIC dye for allele A: GCCGAGGCTAGACCTT CTCT. Re-genotyping of $10 \%$ of the samples was done to assess the validity of the analysis [20].

Briefly, the PCR reaction was done as the following: 10 $\mu \mathrm{l}$ of genotyping master mix (2X), $0.5 \mu \mathrm{l}$ TaqMan assay, 5 $\mu \mathrm{l}$, template DNA, and $4.5 \mu \mathrm{l}$ nuclease-free $\mathrm{H}_{2} \mathrm{O}$ in a total volume of $20 \mu \mathrm{l}$ then components were mixed gently and $15 \mu \mathrm{l}$ of the mixture were dispensed into PCR tubes. According to the standard allelic discrimination genotyping assay protocol, the PCR tubes were placed in the cycler and the PCR cycling program was started. The PCR cycling conditions includes pre-reading of the plate where the background fluorescence is recorded followed by QIAG EN standard PCR protocol of $95^{\circ} \mathrm{C}$ for $10 \mathrm{~min}, 95^{\circ} \mathrm{C}$ for $15 \mathrm{~s}, 60{ }^{\circ} \mathrm{C}$ for $1 \mathrm{~min}$, and repeat steps $2-3$ for 40 cycles (amplification step). With completion of the PCR cycling steps, the post-readings were obtained and described according to the software of the real-time PCR instrument that then plotted. The results of the allelic discrimination run on a scatter plot of Allele 1 versus Allele 2 were shown and each well of the 36-well Rotor is represented as a single point on the plot. Finally, the intensity of fluorescence signals was analyzed by Rotor-Gene Q software series and the readings of allelic discrimination plate were analyzed then the allele types were detected.

\section{Therapy and follow-up of the enrolled patients}

Induction therapy ( $3+7$ protocol) was given as follows: Adriamycin $\left(25 \mathrm{mg} / \mathrm{m}^{2} \mathrm{IV} / 15 \mathrm{~min}\right)$ infusion for 3 days, after which cytarabine was administered $\left(100 \mathrm{mg} / \mathrm{m}^{2} / 12\right.$ h) for 7 days. After achieving CR, the patients were provided three consolidation courses at monthly intervals as continuous IV infusion over $3 \mathrm{~h}$ on days 1,3 , and 5 with a dose of ARA-C cytarabine $\left(3 \mathrm{~g} / \mathrm{m}^{2}\right.$ every $\left.12 \mathrm{~h}\right)$ [21].

After 3 months of induction and consolidation therapy, patients were evaluated by clinical examination, peripheral blood, and BM aspirate.

\section{Patient's clinical outcome}

Patients were assessed at day 28 of induction therapy and then classified into the following: (1) complete remission (CR) (BM blasts < 5\%, absence of circulating blasts, absence of extramedullary disease, absolute neutrophil count $>1.0 \times 10^{9} / \mathrm{L}$, and platelet count $>100 \times$ $10^{9} / \mathrm{L}$ ) and (2) partial remission (PR) (all hematologic criteria of CR; decrease of BM blast percentage to 5$25 \%$ and decrease of pretreatment BM blast percentage 
by at least $50 \%)$. The patients were classified according to the 2017 ELN AML recommendations as follows: favorable clinical outcome (CR) and unfavorable clinical outcome (PR and death) [22]. All patients were followed-up to 6 and 24 months (for living patients) to assess the prognostic impact of hMICL receptor expression and WT1 gene polymorphism.

\section{Statistical methods}

Results were statistically analyzed using statistical package of social sciences (SPSS16.00 IBM/SPSS Inc., and Chicago, IL). Categorical data were expressed as frequency and percentage, Chi-square test was used to compare categorical variables or alternatively, and Fisher's exact test was used when Chi-square assumptions were violated. Normally distributed continuous variables were expressed as mean and standard deviation (mean \pm SD), Student $t$ test was used for comparing normality distributed variables, and Kruskal-Wallis or MannWhitney tests were applied for non-parametric equivalent. Overall survival (OS) and relapse risk were estimated by the Kaplan-Meier method. For overall survival, patients were censored at last follow-up if alive or at the time of allogeneic transplantation. All survival analyses were performed using a Cox model regression and adjusted on protocol as covariate. A P-value $<0.05$ was considered to indicate statistical significance.

\section{Results}

The study included 63 patients with AML, consisting of 36 men and 27 women, with mean age of $47.92 \pm 14.64$ years. Splenomegaly was noted in 23 patients (36.5\%), hepatomegaly was found in 19 patients (30.2\%), while lymphadenopathy was observed in 19 patients (30.2\%). The mean survival rate of the patients was $10.29 \pm 7.54$ (Table 1). Other laboratory details are summarized in Table 1.

hMICL receptor expression was positive in 55 (87.3\%) patients with AML with a mean \pm SD of $64.41 \pm 29.67$. Genotyping of WT1 showed that the AA (wild genotype) was the most prevalent genotype and present in 46 (73\%) patients with AML, followed by AG genotype in $15(23.8 \%)$ patients, while the least prevalent genotype is the GG genotype, which was noted in 2 patients (3.2\%) (Table 2).

Regarding patient's response to therapy at day 28,17 patients (27.0\%) died, and 20 (31.7\%) had CR, while 26 (41.3\%) had PR. At 6 months after therapy, 26 (41.3\%) patients died, 11 (17.4\%) developed relapse, and 26 (41.3\%) achieved CR. At the end of the follow-up period, 37 (58.7\%) patients died or developed relapse, while 26 (41.3\%) patients maintained CR (Table 3).

In the comparison between WT1 AA (wild) and WT1 mutant $(A G+G G)$ genotypes of patients with AML, CR was achieved in $17(100 \%)$ patients with mutant (AG +
Table 1 Descriptive demographic, clinical data of 63 cases of AML

\begin{tabular}{|c|c|c|}
\hline \multirow{2}{*}{$\begin{array}{l}\text { Parameters } \\
\text { Gender }\end{array}$} & \multicolumn{2}{|c|}{ AML cases $(N=63), N(\%)$} \\
\hline & Male & $36(57.1)$ \\
\hline & Female & $27(42.9)$ \\
\hline \multirow[t]{2}{*}{ Hepatomegaly } & Normal & $44(69.8)$ \\
\hline & Enlarged & $19(30.2)$ \\
\hline \multirow[t]{2}{*}{ Splenomegaly } & Normal & $40(63.5)$ \\
\hline & Enlarged & $23(36.5)$ \\
\hline \multirow[t]{2}{*}{ Lymph node } & Normal & $44(69.8)$ \\
\hline & Enlarged & $19(30.2)$ \\
\hline \multirow[t]{6}{*}{ WHO Classification } & MO & $4(6.3)$ \\
\hline & M1 (NOS) & $14(22.2)$ \\
\hline & M2 (NOS) & $27(42.9)$ \\
\hline & M4 (NOS) & $3(4.8)$ \\
\hline & M5 & $14(22.2)$ \\
\hline & M7 & $1(1.6)$ \\
\hline Age (years) & Mean \pm SD & $47.92 \pm 14.64$ \\
\hline Hemoglobin (g/dl) & Mean \pm SD & $7.79 \pm 1.69$ \\
\hline $\operatorname{TLC}\left(\times 10^{9} / \mathrm{L}\right)$ & Mean \pm SD & $46.51 \pm 59.81$ \\
\hline Platelets $\left(\times 10^{9} / \mathrm{L}\right)$ & Mean \pm SD & $69.37 \pm 53.59$ \\
\hline Blast cells (\%) & Mean \pm SD & $59.48 \pm 23.83$ \\
\hline LDH $(I U / d l)$ & Mean \pm SD & $676.11 \pm 615.57$ \\
\hline ALT (IU/dl) & Mean \pm SD & $31.22 \pm 17.66$ \\
\hline AST (IU/dl) & Mean \pm SD & $26.29 \pm 12.06$ \\
\hline Creatinine $(\mathrm{mg} / \mathrm{dl})$ & Mean \pm SD & $1.60 \pm 1.37$ \\
\hline BUN & Mean \pm SD & $31.57 \pm 20.67$ \\
\hline Survival/month & Mean \pm SD & $10.29 \pm 7.54$ \\
\hline
\end{tabular}

$N$ number, $S D$ standard deviation, $N$ number, $T L C$ total leucocytic count

Table 2 Frequency of immunophenotyping, hMICL, and WT1 genotyping in AML cases

\begin{tabular}{llll}
\hline Parameters & \multicolumn{3}{l}{ AML cases $(\boldsymbol{N}=\mathbf{6 3})$} \\
\cline { 2 - 4 } & Positive cases $(\%)$ & Negative cases (\%) & Mean \pm SD \\
\hline CD33 & $58(92.1)$ & $5(7.9)$ & $54.54 \pm 23.07$ \\
CD13 & $54(85.7)$ & $9(14.3)$ & $53.56 \pm 25.85$ \\
CD14 & $7(11.1)$ & $56(88.9)$ & $18.00 \pm 13.42$ \\
CD117 & $44(69.8)$ & $19(30.2)$ & $38.83 \pm 24.85$ \\
MPO & $53(84.1)$ & $10(15.9)$ & $51.00 \pm 26.01$ \\
CD34 & $37(58.7)$ & $26(41.3)$ & $34.51 \pm 27.79$ \\
HLA-Dr & $63(100)$ & $0(0)$ & $40.40 \pm 24.28$ \\
HMICL & $55(87.3)$ & $8(12.7)$ & $64.41 \pm 29.67$ \\
WT1 genotypes & & \\
\multicolumn{1}{c}{ AA } & $46(73.0)$ & & \\
AG & $15(23.8)$ & & \\
GG & $2(3.2)$ & & \\
\hline
\end{tabular}


Table 3 Response to therapy and patient's outcome in all AML cases

\begin{tabular}{lll}
\hline Parameters & AML cases $(\boldsymbol{N}=\mathbf{6 3})$ & \\
\cline { 2 - 3 } & Outcome & N (\%) \\
\hline Response at 28 days: & Died & $17(27.0)$ \\
& CR & $20(31.7)$ \\
& PR & $26(41.3)$ \\
Response at 6 months: & Died & $26(41.3)$ \\
& Relapse & $11(17.4)$ \\
Response at 24 months & CR & $26(41.3)$ \\
& Died or relapse & $37(58.7)$ \\
& CR & $26(41.3)$ \\
\hline
\end{tabular}

$C R$ complete remission, $P R$ partial remission

GG) genotypes but only in $6.4 \%$ of patients with wild genotype (AA) $(\mathrm{p}=0.001)$. After 6 months, CR was recorded in $15(88.2 \%)$ patients with mutant WT1 type, which is more significant than in patients with wild type (23.4\%) $(\mathrm{p}=0.001)$.

The final response event to therapy showed that patients with mutant type significantly achieved higher CR (88.2\%) than patients with wild type (21.3\%), while death and relapse were more frequent in patients with wild subtype $(\mathrm{p}=0.001)$.

In contrast, all other parameters (age, sex, organomegaly, lymphadenopathy, AML phenotype, and other AML-IPT panels) were not different between mutant and wild types, except for CD117, which showed marginal significant relationship $(p=0.047)$ to patients with AA genotype (wild type) (Table 4).

Correlations between hMICL receptor expression and data of patients with AML revealed that eight (100\%) patients with negative hMICL receptor expression achieved $\mathrm{CR}$ at day 28 of therapy, which is significantly increased compared to $12(21.8 \%)$ with positive expression $(p<$ $0.001)$.

At 6 months, all negative cases for hMICL receptor expression had maintained CR, which is significantly increased compared to cases with positive expression $(p=$ 0.001). The final event of therapy response recorded that all negative cases of hMICL receptor expression were still in CR.

Splenomegaly was more frequent among positive cases of hMICL receptor expression (36 [65.5\%]). On the other hand, there was no statistically significant relation between hMICL receptor expression and other clinical features of patients such as age, sex, hepatomegaly, lymphadenopathy, AML phenotype, and other IPT panels, except for Table 5 .

As shown in Table 6, there was no statistically significant difference between WT1 genotypes and other data (age, sex, and laboratory data). There was a significant increase in the survival months in patients with mutant genotypes (GG and AG) compared to patients with wild type (AA) $(18.9 \pm 4.6$ months vs. $7.1 \pm 5.7$ months and p-value $=0.001)($ Fig. 1).

There was a significant decrease in blast count in patients with positive hMICL receptor expression compared to that in patients with negative expression ( $\mathrm{p}$ $=0.02$ and $\mathrm{p}=0.001$ respectively). No significant difference was found between other data (age, sex, and laboratory data) and hMICL receptor expression (Table 6).

Overall survival (OS) in patients who had positive hMICL receptor expression was $8.6 \pm 6.5$ months, which was significantly shorter compared to that in patients with negative hMICL receptor expression $\left(x^{2}=9.328, p\right.$ $=0.002$ ) (Fig. 2).

\section{Discussion}

CN-AML is the largest cytogenetic group of AMLs. Understanding the pattern of gene mutation in this patient group has an increasing influence on prognosis, treatment, and options for MRD [4]. WT1 is highly expressed in various types of leukemia, which has advanced its position as both a target for immunotherapy and a means of monitoring MRD [23].

The most important issue of the IPT in AML is the lack of constancy of antigen expression during the disease and that antigen densities for many antigens are identical on leukemic blasts and normal progenitors [24].

hMICL is a stable marker at diagnosis and during follow-up and is homogenously present on the CD34positive patients, who can be otherwise poorly lineagecharacterized IPT and difficult to monitor for MSD [25].

The current study investigated the relationship between WT1 genotypes and the promising marker hMICL receptor expression in 63 patients with CN-AML and determined the treatment outcome in these patients.

Regarding genotyping of WT1, the current study showed that the minor (mutant) allele of WT1 SNP rs 16754 was found in $26.89 \%$ of patients with AML at the heterozygous state (AG), and in $23.8 \%$ of patients with homozygous state (GG), while the wild type (AA) was reported in $57.14 \%$ of patients with AML.

These frequencies are like those previously reported by Renneville et al. [26], who found that the minor allele of WT1 SNP rs16754 was expressed in 141 of 511 (27.6\%) patients, at the heterozygous state (AG) in 123 patients (24\%) and homozygous state (GG) in 18 patients (3.6\%).

The same frequencies were reported by Hollink et al., Damm et al., and Ho et al. [27-29] However, in an old study by King-Underwood and Pritchard-Jones, they reported that mutations in WT1 occurred in only $10-15 \%$ of patients [30]. 
Table 4 Comparison between WT1 genotyping and AML patients' data

\begin{tabular}{|c|c|c|c|c|}
\hline \multirow[t]{2}{*}{ Parameters } & \multirow[t]{2}{*}{ Variables } & \multicolumn{2}{|l|}{ WT1 $(N=63)$} & \multirow[t]{2}{*}{$P$ value } \\
\hline & & GG + AG (mutant) $(N=17)$ & AA (wild) $(N=46)$ & \\
\hline \multirow[t]{2}{*}{ Gender } & Male & $8(47.1 \%)$ & $28(60.9 \%)$ & 0.395 \\
\hline & Female & $9(52.9 \%)$ & $18(39.1 \%)$ & \\
\hline \multirow[t]{2}{*}{ Liver } & Normal & $12(70.6 \%)$ & $32(69.6 \%)$ & 0.937 \\
\hline & Enlarged & $5(29.4 \%)$ & $14(30.4 \%)$ & \\
\hline \multirow[t]{2}{*}{ Spleen } & Normal & $10(58.8 \%)$ & $30(62.2 \%)$ & 0.770 \\
\hline & Enlarged & $7(41.2 \%)$ & $16(34.8 \%)$ & \\
\hline \multirow[t]{2}{*}{ Lymph node } & Normal & $9(52.9 \%)$ & $35(70.1 \%)$ & 0.076 \\
\hline & Enlarged & $8(47.1 \%)$ & $11(23.9 \%)$ & \\
\hline \multirow[t]{3}{*}{ Response (28 days) } & Died & $0(0 \%)$ & 17 (36.9\%) & 0.001 \\
\hline & $C R$ & 17 (100\%) & $3(6.4 \%)$ & \\
\hline & PR & $0(0 \%)$ & $26(56.5 \%)$ & \\
\hline \multirow[t]{3}{*}{ Response (6 months) } & Died & $1(5.9 \%)$ & $25(54.3 \%)$ & 0.001 \\
\hline & $C R$ & 15 (88.2\%) & $11(23.4 \%)$ & \\
\hline & Relapse & $1(5.8 \%)$ & $10(21.7 \%)$ & \\
\hline \multirow[t]{2}{*}{ Response (24 months) } & Died or relapse & $2(11.8 \%)$ & $36(78.3 \%)$ & 0.001 \\
\hline & $C R$ & 15 (88.2\%) & $10(21.3 \%)$ & \\
\hline \multirow[t]{6}{*}{ AML subtype } & MO & $2(11.8 \%)$ & $2(4.3 \%)$ & 0.139 \\
\hline & M1 & $5(29.4 \%)$ & $9(19.6 \%)$ & \\
\hline & M2 & $8(40.1 \%)$ & $19(41.3 \%)$ & \\
\hline & M4 & $0(0 \%)$ & $3(65.2 \%)$ & \\
\hline & M5 & $1(5.9 \%)$ & $13(28.3 \%)$ & \\
\hline & M7 & $1(5.9 \%)$ & $0(0 \%)$ & \\
\hline \multirow[t]{12}{*}{ Immunophenotyping } & CD33- & $3(17.6 \%)$ & $2(4.3 \%)$ & 0.117 \\
\hline & CD33+ & $14(82.4 \%)$ & $44(95,6 \%)$ & \\
\hline & CD13- & $2(11.8 \%)$ & $7(15.2 \%)$ & 0.542 \\
\hline & CD13+ & 15 (88.2\%) & $39(84.8 \%)$ & \\
\hline & CD14- & 15 (88.2\%) & $41(89.1 \%)$ & 0.615 \\
\hline & CD14+ & $2(11.8 \%)$ & $5(10.9 \%)$ & \\
\hline & CD117- & $2(11.8 \%)$ & $17(36.2 \%)$ & 0.047 \\
\hline & CD117+ & 15 (88.2\%) & $29(61.7 \%)$ & \\
\hline & MPO- & $5(39.4 \%)$ & $5(10.9 \%)$ & 0.085 \\
\hline & $\mathrm{MPO}+$ & $12(60.6 \%)$ & 41 (89.1\%) & \\
\hline & CD34- & $6(35.3 \%)$ & $20(34.5 \%)$ & 0.386 \\
\hline & CD34+ & $11(64.7 \%)$ & $26(56.5 \%)$ & \\
\hline
\end{tabular}

$C R$ complete remission, $P R$ partial remission

In the current study, $\mathrm{CR}$ was achieved in all AML cases with mutant AG plus GG WT1 genotypes. Also, the OS in mutant WT1 was significantly longer compared to that in wild type (AA). These findings suggest a favorable outcome for patients with mutant WT1 genotypes.

Our results agreed with those of Megías-Vericat et al. who reported in their meta-analysis that both 5 years survival and disease-free survival (DFS) were significantly higher in patients with the variant allele $(G)$ although they did not find any significant effect of this variant on CR [1]. Similar results were reported by Long et al. [11] and Petiti et al. [31].

Similarly, two studies by Damm et al. and Ho et al., one performed in adult CN-AML and the other in pediatric AML, reported that the minor allele of WT1 SNP rs16754 significantly improved clinical outcome [28, 29]. 
Table 5 Comparison between hMICL expression and AML patients' data

\begin{tabular}{|c|c|c|c|c|}
\hline \multirow[t]{2}{*}{ Parameters } & \multirow[t]{2}{*}{ Variables } & \multicolumn{2}{|l|}{ HMICL $(N=63)$} & \multirow[t]{2}{*}{$P$ value } \\
\hline & & Negative $(N=8)$ & Positive $(N=55)$ & \\
\hline \multirow[t]{2}{*}{ Gender: } & Male & $4(50 \%)$ & $23(41.8 \%)$ & 0.473 \\
\hline & Female & $4(50 \%)$ & $32(58.2 \%)$ & \\
\hline \multirow[t]{2}{*}{ Liver } & Normal & $6(75 \%)$ & 38 (69.1\%) & 0.545 \\
\hline & Enlarged & $2(25 \%)$ & $17(30.1 \%)$ & \\
\hline \multirow[t]{2}{*}{ Spleen } & Normal & $4(50 \%)$ & $36(65.5 \%)$ & 0.0318 \\
\hline & Enlarged & $4(50 \%)$ & 19 (34.6\%) & \\
\hline \multirow[t]{2}{*}{ Lymph node } & Normal & $5(62.5 \%)$ & 39 (70.9 \%) & 0.455 \\
\hline & Enlarged & $3(37.5 \%)$ & $16(29.1 \%)$ & \\
\hline \multirow[t]{3}{*}{ Response (28 days) } & Died & $0(0 \%)$ & 17 (30.9\%) & 0.001 \\
\hline & $C R$ & $8(100 \%)$ & $12(21.8 \%)$ & \\
\hline & PR & $0(0 \%)$ & $26(47.3 \%)$ & \\
\hline \multirow[t]{3}{*}{ Response (6 months) } & Died & $0(0 \%)$ & $26(47.3 \%)$ & 0.001 \\
\hline & $C R$ & $8(100 \%)$ & $11(20.0 \%)$ & \\
\hline & $P R$ & $0(0 \%)$ & $18(32.7 \%)$ & \\
\hline \multirow[t]{2}{*}{ Response (24 months) } & Died or relapse & $0(\%)$ & $37(67.3 \%)$ & 0.001 \\
\hline & $C R$ & $8(100 \%)$ & $18(32.7 \%)$ & \\
\hline \multirow[t]{6}{*}{ AML subtype } & MO & $1(12.5 \%)$ & $3(5.5 \%)$ & 0.138 \\
\hline & M1 & $2(25 \%)$ & $12(21.8 \%)$ & \\
\hline & M2 & $3(37.5 \%)$ & $24(43.6 \%)$ & \\
\hline & M4 & $0(0 \%)$ & $3(5.5 \%)$ & \\
\hline & M5 & $1(12.5 \%)$ & $13(23.6 \%)$ & \\
\hline & M7 & $1(12.5 \%)$ & $0(0 \%)$ & \\
\hline \multirow[t]{12}{*}{ Immunophenotyping } & CD33- & $1(12.5 \%)$ & $4(7.3 \%)$ & 0.505 \\
\hline & CD33+ & $7(87.2 \%)$ & $51(92.7 \%)$ & \\
\hline & CD13- & $2(25 \%)$ & $7(12.7 \%)$ & 0.320 \\
\hline & CD13+ & $6(75 \%)$ & $48(87.3 \%)$ & \\
\hline & CD14- & $6(75 \%)$ & $50(90.9 \%)$ & 0.214 \\
\hline & CD14+ & $2(25 \%)$ & $5(9.1 \%)$ & \\
\hline & CD117- & $2(25 \%)$ & $17(30.9 \%)$ & 0.545 \\
\hline & CD117+ & $6(75 \%)$ & $38(69.1 \%)$ & \\
\hline & MPO- & $3(37.5 \%)$ & $7(12.7 \%)$ & 0.106 \\
\hline & $\mathrm{MPO}+$ & $5(62.5 \%)$ & $48(87.3 \%)$ & \\
\hline & CD34- & $4(50 \%)$ & $22(40 \%)$ & 0.433 \\
\hline & CD34+ & $4(50 \%)$ & $33(60 \%)$ & \\
\hline
\end{tabular}

$C R$ complete remission, $P R$ partial remission

However, a large cancer and leukemia group study reported by Becker et al. found that patients with $\mathrm{CN}$ AML who had the rs16754 (WT1GG) genotype had a more favorable outcome among a subset of patients with FLT3-ITD [32].

Choi et al. in a Korean cohort study revealed that the different genotypes of rs16754 did not have any significant impact on clinical outcome in CN-AML [33].
Similarly, Rennevill et al., Ramzi et al., and Marcucci et al. found no significant difference between patients with wild and variant alleles based on CR and relapse as well as OS and DFS and adults and Hollink et al. found no prognostic impact of this SNP in pediatric AML $[26,27,34,35]$. This difference can be explained by differences in sample size, laboratory methods racial, and age variations. 
Table 6 Comparison between WT1 genotyping and hMICL expression to basal laboratory data of AML patients

\begin{tabular}{|c|c|c|c|c|c|c|}
\hline \multirow{2}{*}{$\begin{array}{l}\text { Parameters } \\
(M \pm S D)\end{array}$} & \multicolumn{2}{|l|}{ WT1 $(N=63)$} & \multirow[t]{2}{*}{$P$ value } & \multicolumn{2}{|l|}{ HMICL $(N=63)$} & \multirow[t]{2}{*}{$P$ value } \\
\hline & $\mathrm{GG}+\mathrm{AG}(N=17)$ & $\mathrm{AA}(N=46)$ & & Negative $(N=8)$ & Positive $(N=55)$ & \\
\hline Age & $49.1 \pm 16.5$ & $47.5 \pm 14.1$ & 0.719 & $54.4 \pm 17.8$ & $47.0 \pm 14.0$ & 0.292 \\
\hline TLC & $47.1 \pm 45.9$ & $56.2 \pm 54.3$ & 0.951 & $64.0 \pm 61.0$ & $54.0 \pm 50.0$ & 0.408 \\
\hline HB & $8.1 \pm 1.8$ & $7.7 \pm 1.6$ & 0.477 & $7.6 \pm 1.6$ & $7.8 \pm 1.7$ & 0.758 \\
\hline Platelets & $92.5 \pm 60.9$ & $81.2 \pm 72.5$ & 0.654 & $87.3 \pm 73.1$ & $75.2 \pm 66.7$ & 0.680 \\
\hline Blast count & $63.6 \pm 22.7$ & $57.9 \pm 24.3$ & 0.392 & $75.7 \pm 17.2$ & $57.1 \pm 23.8$ & 0.020 \\
\hline LDH & $882 \pm 714$ & $600 \pm 564$ & 0.154 & $927 \pm 873$ & $647 \pm 563$ & 0.522 \\
\hline ALT & $29.6 \pm 15.8$ & $31.8 \pm 18.4$ & 0.649 & $35.8 \pm 16.3$ & $30.5 \pm 17.8$ & 0.415 \\
\hline AST & $23.3 \pm 7.9$ & $27.4 \pm 13.1$ & 0.148 & $23.5 \pm 10.2$ & $26.7 \pm 12.3$ & 0.439 \\
\hline Creatinine & $1.4 \pm 0.9$ & $1.7 \pm 1.5$ & 0.414 & $1.1 \pm 0.8$ & $1.7 \pm 1.4$ & 0.142 \\
\hline BUN & $26.8 \pm 13.7$ & $33.3 \pm 22.6$ & 0.168 & $24.3 \pm 13.0$ & $32.6 \pm 21.4$ & 0.154 \\
\hline Survival (months) & $18.9 \pm 4.6$ & $7.1 \pm 5.7$ & 0.000 & $21.8 \pm 2.0$ & $8.6 \pm 6.5$ & 0.001 \\
\hline
\end{tabular}

Niavarani et al. found good prognostic effect of another WT1 mutation, which is WT1 rs2234593 variant mutation. This supports our finding that exon 7 mutation of this gene carries good prognosis for CN-AML [21].

On the contrary, King-Underwood and PritchardJones suggested that WT1 mutation may represent a poor prognostic indicator in AML [30]. In support of this study, Nyvold et al. noted the emergence of a WT1mutated subclone following therapy, suggesting that mutation of WT1 could lead to progression of leukemia by conferring drug resistance [36]. Furthermore, Fitzgibbon et al. reported an association between acquired uniparental disomy of $11 \mathrm{p}$ and homozygous mutation of WT1 in patients with AML [37].

Owen et al. found a possible negative impact in AML with concurrent WT1 and FMS-like tyrosine kinase 3 (FLT3)-internal tandem duplication (ITD) mutations [38]. This discrepancy may be explained by three reasons: First, their AML cases had FLT3-ITD in addition to WT1 mutation and combined cytogenetic abnormality. Second, they used a clustering of mutations to exons in WT1 by fluorescence-based capillary electrophoresis analysis, which has provided different results. Lastly, their group included AML and ALL together in the survival analysis.

\section{Survival Functions}

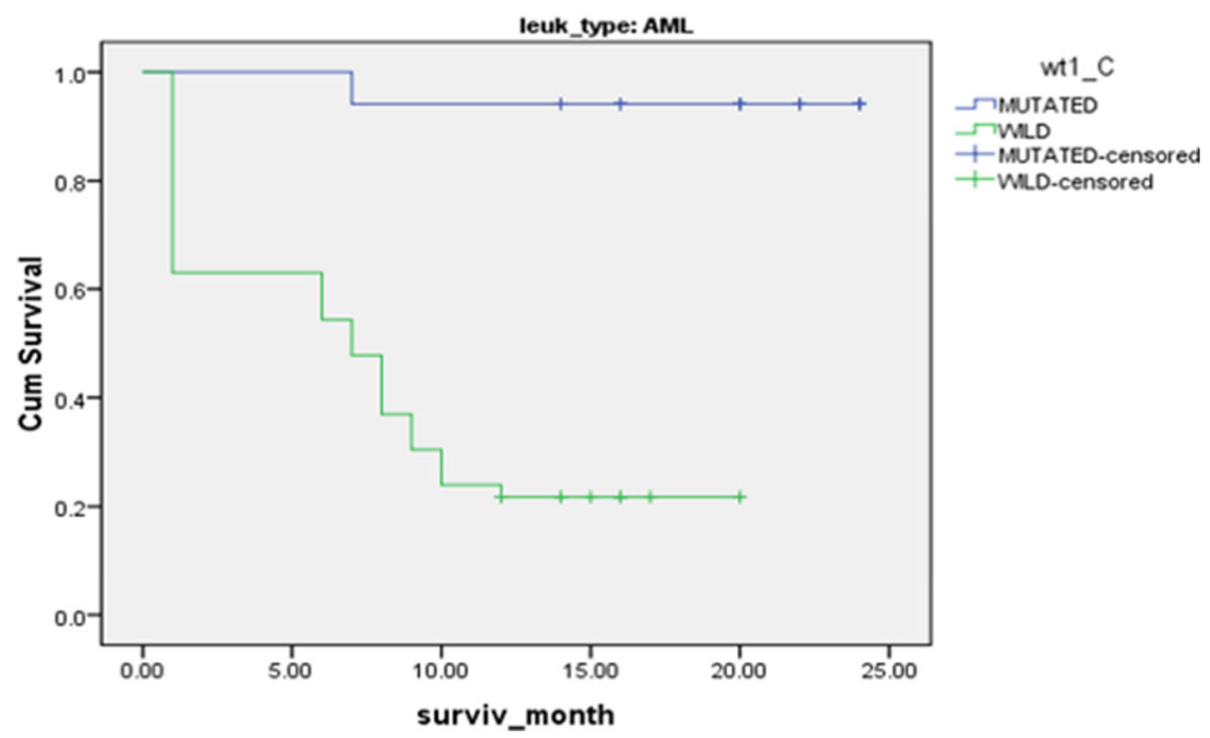

Fig. 1 Kaplan-Meier survival curve in AML patients with wild and mutant WT1 genotypes 


\section{Survival Functions}
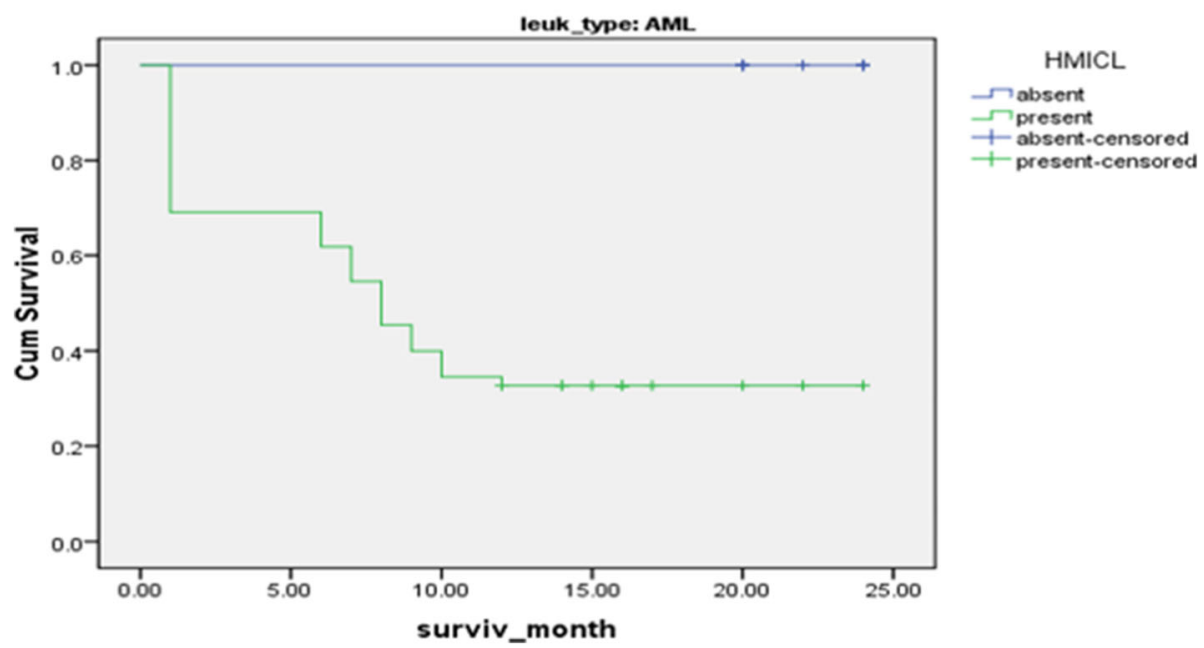

Fig. 2 Kaplan-Meier survival curve in AML patients with positive and negative hMICL receptor expressions

Of note, WT1 SNP rs16754 status did not correlate with the total WT1 messenger ribonucleic acid (mRNA) expression level in two previous studies [28, 29]. In addition, the SNP of WT1 (rs16754) consists of the replacement of a CGA by a CGG codon, which is used two times more often than the CGA to encode arginine.

Thus, the presence of the WT1 SNP rs16754 is increasing the rate of translation, which potentially affects protein folding. The location of WT1 rs16754 in exon 7 SNP rs16754 may not affect the splicing process [26].

The role of SNP rs16754 cannot exclude its possibility in linkage disequilibrium with another genetic aberration that affects drug metabolism and sensitivity. Confounding factors related to patient and disease characteristics, such as age, study restriction to $\mathrm{CN}-\mathrm{AML}$, and other accompanying genetic alterations may account for the discordant results recorded regarding the impact of WT1 SNP rs16754 genotype on prognosis.

Differences in treatment protocols between cooperative groups may also be responsible for these contradictory results. The various dosages of cytarabine in postremission treatment for AML were shown to be related to somatic molecular abnormalities Rat Sarcoma Viral Oncogene (RAS) mutations [39]. One can hypothesize that leukemic cells harboring WT1 SNP rs16754 minor allele may be more sensitive to treatment by cytarabine, which was used in our current study.

Additionally, no significant relationship was detected between pretreatment patient parameters (age, sex, organomegaly, lymphadenopathy, AML phenotype, or other AML-IPT panels) and mutant or wild type. In agreement with our findings, Renneville et al. [26] and Schmid and his colleagues failed to correlate WT1 gene expression with other features of leukemia [40].

In the current study, we found that hMICL receptor expression was positive on leukemic cells in most patients with CN-AML. In agreement with our finding, van Rhenen et al. acknowledged hMICL as a surface antigen expressed on aCD34-positive AML and considered the antigen as a possible target in antibodymediated therapy [41]. Several studies suggest that the routine use of hMICL can increase the value of FCM in diagnosis of AML [42].

Furthermore, Larsen et al. reported that hMICL was found in approximately $92 \%$ of studied patients with AML patients. Also, they reported that it was absent on lymphoid blast cells in all studied cases suggesting its specificity and potential value as a marker to discriminate AML from ALL in a routine FCM examination and revealed the validity of this antigen as a stable pan-AML marker that can increase both the diagnostic accuracy and MRD marker identification by FCM in AML cases during therapy and treatment follow-up [14].

To explore the prognostic impact of hMICL expression, response to treatment analysis revealed that all patients with negative hMICL expression achieved CR at day 28 of therapy and maintained CR till the end of follow-up period (24 months).

However, there was no statistically significant difference between $h M I C L$ expression and patients features, such as age, sex, hepatomegaly, lymphadenopathy, AML phenotype, and other IPT panels. 
In agreement with our results, Bakker et al. recorded no significant difference between hMICL expression and different $\mathrm{FAB}$ subtypes studied, except for M3 cases, which recorded the highest expression of hMICL [43].

The OS was significantly longer in patients with negative hMICL expression compared to patients with positive hMICL expression. This suggested its important role in the selection of cases with good response to therapy.

In contrast to our results, Roug et al. found no relationship between disease remission and hMICL percentage expression [15]. Also, Eissa et al. found stable expression of hMICL through the disease and questioned the value of hMICL-based IPT in detection of treatment failure, which unfortunately happens in most patients with AML [44].

The current study had some limitations due to the small number of patients and short follow-up period so a larger study with longer follow-up period is recommended.

\section{Conclusion}

WT1 SNP rs16754 has significant impact on clinical outcome of CN-AML. This would allow rapid selection of patients with good prognosis suitable for chemotherapy protocol. Because of conflicting data in the literature, further large-scale studies are needed to clarify the relationship between WT1 mutations and treatment outcome in AML to firmly establish their prognostic significance in AML. Additionally, the current data identify hMICL as an AML-associated antigen and establish its possible applicability for diagnosis and prognosis of patients with AML in a standard FCM setting.

\section{Abbreviations}

AML: Acute myeloid leukemia; CR: Complete remission; BM: Bone marrow; MRD: Minimal residual disease; CN-AML: Cytogenetically normal-acute myeloid leukemia; WT1: Wilms tumor 1; SNP: Single nucleotide polymorphism; hMICL: Human myeloid inhibitory C-type lectin-like receptor; LSCs: Leukemic stem cells; ALL: Acute lymphoblastic leukemia; MDS: Myelodysplastic syndrome; CT: Computed tomography; CNS: Central nervous system; IPT: Immunophenotyping; PCR: Polymerase chain reaction; PR: Partial remission; OS: Overall survival; DFS: Disease-free survival; FLT3-ITD: FMS-like tyrosine kinase 3- internal tandem duplication; mRNA: Messenger ribonucleuc acid; RAS: Rat Sarcoma Viral Oncogene

\section{Acknowledgements}

The authors thank all participants for their participation and cooperation.

\section{Authors' contributions}

SG and MA analyzed and interpreted the patient data regarding the hematological disease, treatment, and follow-up. HB and HR performed the laboratory work. FK and SB interpreted the data. All authors equally contributed to writing the manuscript. The authors read and approved the final manuscript.

\section{Availability of data and materials}

All data generated or analyzed during this study are included in this published article.

\section{Declarations}

\section{Ethics approval and consent to participate}

Either verbal or written consents were obtained from all subjects before their enrollment in the study. The study protocol was in accordance with the Declaration of Helsinki and approved by the Scientific and Ethical Committee of National Liver Institute, Menoufia University. The committee's reference number is not available.

\section{Consent for publication}

Not applicable.

\section{Competing interests}

The authors declare that there are no competing interests.

\section{Author details}

${ }^{1}$ Departments of Clinical Pathology, National Liver Institute, Menoufia University, Al Minufiyah, Egypt. ${ }^{2}$ Internal Medicine Department, Faculty of Medicine, Ain Shams University, Cairo, Egypt. ${ }^{3}$ Clinical Oncology Department, Faculty of Medicine, Menoufia University, Al Minufiyah 32511, Egypt. ${ }^{4}$ shibin elkom, Egypt. ${ }^{5}$ Biochemistry, National Liver Institute, Menoufia University, Al Minufiyah, Egypt. ${ }^{6}$ Pharmacology Department, Faculty of Medicine, Al Azhar University, Cairo, Egypt.

Received: 10 February 2021 Accepted: 3 June 2021

Published online: 12 July 2021

\section{References}

1. Megías-Vericat JE, Herrero MJ, Rojas L, Montesinos P, Bosó V, Moscardó F. Martínez-Cuadrón D, Poveda JL, Sanz MÁ, Aliño SF (2016 Feb) A systematic review and meta-analysis of the impact of WT1 polymorphism rs16754 in the effectiveness of standard chemotherapy in patients with acute myeloid leukemia. The pharmacogenomics journals. 16(1):30-40. https://doi.org/10.1 038/tpj.2015.80

2. Zhou F, Chen B (2018 Oct 21) Acute myeloid leukemia carrying ETV6 mutations: biologic and clinical features. Hematology. 23(9):608-612. https:// doi.org/10.1080/10245332.2018.1482051

3. Bachas C, Schuurhuis GJ, Assaraf YG, Kwidama ZJ, Kelder A, Wouters F, Snel AN, Kaspers GJL, Cloos J (2012 Jun) The role of minor subpopulations within the leukemic blast compartment of AML patients at initial diagnosis in the development of relapse. Leukemia. 26(6):1313-1320. https://doi.org/10.1038/ leu.2011.383

4. Wang J, Wang W, Chen H, Li W, Huang T, Zhang W, Ling W, Lai P, Wang Y, Geng S, Li M (2021) C-type lectin-like molecule-1 as a biomarker for diagnosis and prognosis in acute myeloid leukemia: a preliminary study. BioMed research international. 12:2021

5. Paietta E. Minimal residual disease in acute myeloid leukemia: coming of age. Hematology 2010, the American Society of Hematology Education Program Book. 2012 Dec 8;2012(1):35-42.

6. Paietta $\mathrm{E}$ (2012) When it comes to MRD, AML $\neq A L L$. Blood, The Journal of the American Society of Hematology. 120(8):1536-1537

7. Vora A, Goulden N, Wade R, Mitchell C, Hancock J, Hough R, Rowntree C, Richards S (2013) Treatment reduction for children and young adults with low-risk acute lymphoblastic leukaemia defined by minimal residual disease (UKALL 2003): a randomised controlled trial. The lancet oncology. 14(3):199209. https://doi.org/10.1016/S1470-2045(12)70600-9

8. Ariyaratana S, Loeb DM (2007) The role of the Wilms tumour gene (WT1) in normal and malignant haematopoiesis. Expert reviews in molecular medicine. 9(14):1-17. https://doi.org/10.1017/S1462399407000336

9. Maurer U, Brieger J, Weidmann E, Mitrou PS, Hoelzer D, Bergmann L (1997) The Wilms' tumor gene is expressed in a subset of CD34+ progenitors and downregulated early in the course of differentiation in vitro. Experimental hematology. 25(9):945-950

10. Gaidzik VI, Schlenk RF, Moschny S, Becker A, Bullinger L, Corbacioglu A, Krauter J, Schlegelberger B, Ganser A, Döhner H, Döhner K, German-Austrian AML Study Group (2009) Prognostic impact of WT1 mutations in cytogenetically normal acute myeloid leukemia: a study of the German- 
Austrian AML Study Group. Blood. 113(19):4505-4511. https://doi.org/10.11 82/blood-2008-10-183392

11. Long J, Fang S, Dai Q, Liu X, Zhu W, Wang S (2016) The Wilms tumor-1 (WT1) rs16754 polymorphism is a prognostic factor in acute myeloid leukemia (AML): a meta-analysis. Oncotarget. 7(22):32079-32087. https://doi. org/10.18632/oncotarget.8117

12. Cilloni D, Renneville A, Hermitte F, Hills RK, Daly S, Jovanovic JV, Gottardi E, Fava M, Schnittger S, Weiss T, Izzo B, Nomdedeu J, van der Heijden A, van der Reijden BA, Jansen JH, van der Velden VHJ, Ommen H, Preudhomme C, Saglio G, Grimwade D (2009) Real-time quantitative polymerase chain reaction detection of minimal residual disease by standardized WT1 assay to enhance risk stratification in acute myeloid leukemia: a European LeukemiaNet study. Journal of Clinical Oncology. 27(31):5195-5201. https:// doi.org/10.1200/JCO.2009.22.4865

13. Ujj Z, Buglyó G, Udvardy M, Beyer D, Vargha G, Biró S, Rejtő L (2016) WT1 expression in adult acute myeloid leukemia: assessing its presence, magnitude, and temporal changes as prognostic factors. Pathology \& Oncology Research. 22(1):217-221. https://doi.org/10.1007/s12253-015-0002-0

14. Larsen $H \varnothing$, Roug $A S$, Just $T$, Brown $G D$, Hokland P (2012) Expression of the hMICL in acute myeloid leukemia—a highly reliable disease marker at diagnosis and during follow-up. Cytometry Part B: Clinical Cytometry. 82(1): 3-8. https://doi.org/10.1002/cyto.b.20614

15. Roug $A S$, Larsen $H \varnothing$, Nederby L, Just $T$, Brown G, Nyvold CG, Ommen HB, Hokland P (2014) h MICL and CD 123 in combination with a CD 45/CD 34/ CD 117 backbone-a universal marker combination for the detection of minimal residual disease in acute myeloid leukaemia. British journal of haematology. 164(2):212-222. https://doi.org/10.1111/bjh.12614

16. Arber DA, Orazi A, Hasserjian R, Thiele J, Borowitz MJ, Le Beau MM et al (2016) The 2016 revision to the World Health Organization classification of myeloid neoplasms and acute leukemia. Blood. 127(20):2391-2405. https:// doi.org/10.1182/blood-2016-03-643544

17. Bennett JM, Catovsky D, Daniel MT, Flandrin G, Galton DA, Gralnick HR (1985) at al. Proposed revised criteria for the classification of acute myeloid leukemia: a report of the French-American-British Cooperative Group. Annals of internal medicine. 103(4):620-625. https://doi.org/10.7326/0003-4 819-103-4-620

18. Wan TS (2014) Cancer cytogenetics: methodology revisited. Annals of laboratory medicine. 34(6):413-425. https://doi.org/10.3343/alm.2014.34. 6.413

19. Kaleem Z, Crawford E, Pathan MH, Jasper L, Covinsky MA, Johnson LR, White G (2003 Jan) Flow cytometric analysis of acute leukemias: diagnostic utility and critical analysis of data. Archives of pathology \& laboratory medicine. 127(1):42-48. https://doi.org/10.5858/2003-127-42-FCAOA

20. Opitz JM. Book review ISCN 2013: An international system for human cytogenetic nomenclature (2013). Shaffer LG, McGowan-Jordan J, Schmid M, editors. Published in collaboration with Cytogenetic and Genome Research by Karger, Basel. VI and 140 pp. plus fold-out, 11 Fig. 4 tables.

21. Niavarani A, Horswell S, Sadri R, Bonnet D (2016) The Wilms Tumor-1 (WT1) rs2234593 variant is a prognostic factor in normal karyotype acute myeloid leukemia. Annals of hematology. 95(2):179-190. https://doi.org/10.1007/s002 77-015-2534-5

22. Dillman RO, Davis RB, Green MR, Weiss RB, Gottlieb AJ, Caplan S, et al. A comparative study of two different doses of cytarabine for acute myeloid leukemia: a phase III trial of Cancer and Leukemia Group B.

23. Yang L, Han Y, Saiz FS, Minden MD (2007) A tumor suppressor and oncogene: the WT1 story. Leukemia. 21(5):868-876. https://doi.org/10.1038/ sj.leu.2404624

24. Li X, Du W, Liu W, Li X, Li H, HUANG SA (2010) Comprehensive flow cytometry phenotype in acute leukemia at diagnosis and at relapse. Apmis. 118(5):353-359. https://doi.org/10.1111/j.1600-0463.2010.02603.x

25. Kern W, Bacher U, Haferlach C, Schnittger S, Haferlach T (2010) The role of multiparameter flow cytometry for disease monitoring in AML. Best practice \& research Clinical haematology. 23(3):379-390. https://doi.org/10.1016/j. beha.2010.06.007

26. Renneville A, Boissel N, Helevaut N, Nibourel O, Terré C, Pautas C, Gardin C, Thomas X, Turlure P, Reman O, Berthon C, Dombret H, Castaigne S, Preudhomme C (2011) Wilms' tumor 1 single-nucleotide polymorphism rs 16754 does not predict clinical outcome in adult acute myeloid leukemia. Leukemia. 25(12):1918-1921. https://doi.org/10.1038/leu.2011.173

27. Hollink IH, van den Heuvel-Eibrink MM, Zimmermann M, Balgobind BV, ArentsenPeters ST, Alders M et al (2010) No prognostic impact of the WT1 gene single nucleotide polymorphism rs16754 in pediatric acute myeloid leukemia. J Clin Oncol. 28(28):e523-e526. https://doi.org/10.1200/JCO.2010.29.3860

28. Damm F, Heuser M, Morgan M, Yun H, Großhennig A, Göhring G, Schlegelberger B, Döhner K, Ottmann O, Lübbert M, Heit W, Kanz L, Schlimok G, Raghavachar A, Fiedler W, Kirchner H, Döhner H, Heil G, Ganser A, Krauter J (2010) Single nucleotide polymorphism in the mutational hotspot of WT1 predicts a favorable outcome in patients with cytogenetically normal acute myeloid leukemia. Journal of Clinical Oncology. 28(4):578-585. https://doi.org/10.1200/JCO.2009.23.0342

29. Ho PA, Kuhn J, Gerbing RB, Pollard JA, Zeng R, Miller KL, Heerema NA, Raimondi SC, Hirsch BA, Franklin JL, Lange B (2011) WT1 synonymous single nucleotide polymorphism rs 16754 correlates with higher mRNA expression and predicts significantly improved outcome in favorable-risk pediatric acute myeloid leukemia: a report from the children's oncology group. Journal of clinical oncology. 29(6):704-711. https://doi.org/10.1200/JCO.201 0.31 .9327

30. King-Underwood L, Pritchard-Jones K (1998) Wilms' tumor (WT1) gene mutations occur mainly in acute myeloid leukemia and may confer drug resistance. Blood, The Journal of the American Society of Hematology. 91(8):2961-2968

31. Petiti J, Rosso V, lacono ML, Calabrese C, Signorino E, Gaidano V et al (2018) Prognostic significance of the Wilms' tumor-1 (WT1) rs16754 polymorphism in acute myeloid leukemia. Leukemia research. 67:6-11. https://doi.org/10.1 016/.leukres.2018.01.016

32. Becker H, Maharry K, Radmacher MD, Mrózek K, Metzeler KH, Whitman SP et al (2011) Clinical outcome and gene-and microRNA-expression profiling according to the Wilms tumor 1 (WT1) single nucleotide polymorphism rs16754 in adult de novo cytogenetically normal acute myeloid leukemia: a Cancer and Leukemia Group B study. haematologica 96(10):1488

33. Choi Y, Lee JH, Hur EH, Kang MJ, Kim SD, Lee JH, Kim DY, Lim SN, Bae KS, Lim HS, Seol M, Kang YA, Lee KH (2012) Single nucleotide polymorphism of Wilms' tumor 1 gene rs16754 in Korean patients with cytogenetically normal acute myeloid leukemia. Annals of hematology. 91(5):671-677. https://doi.org/10.1007/s00277-011-1355-4

34. Ramzi M, Moghadam M, Cohan N (2019) Wilms tumor-1 (WT1) rs16754 polymorphism and clinical outcome in acute myeloid leukemia. Turkish Journal of Haematology. 36(1):67-68. https://doi.org/10.4274/tjh.galenos.201 8.2018 .0277

35. Marcucci G, Haferlach T, Döhner H (2011) Molecular genetics of adult acute myeloid leukemia: prognostic and therapeutic implications. Journal of Clinical Oncology. 29(5):475-486. https://doi.org/10.1200/JCO.2 010.30 .2554

36. Nyvold CG, Stentoft J, Braendstrup K, Melsvik D, Moestrup SK, JuhlChristensen $C$ et al (2006) Wilms' tumor 1 mutation accumulated during therapy in acute myeloid leukemia: biological and clinical implications. Leukemia. 20(11):2051-2054. https://doi.org/10.1038/sj. leu.2404389

37. Fitzgibbon J, Smith LL, Raghavan M, Smith ML, Debernardi S, Skoulakis S, Lillington D, Lister TA, Young BD (2005) Association between acquired uniparental disomy and homozygous gene mutation in acute myeloid leukemias. Cancer research. 65(20):9152-9154. https://doi.org/10.1158/00085472.CAN-05-2017

38. Owen C, Fitzgibbon J, Paschka P (2010) The clinical relevance of Wilms tumour 1 (WT1) gene mutations in acute leukaemia. Hematological oncology. 28(1):13-19. https://doi.org/10.1002/hon.931

39. Neubauer A, Maharry K, Mrózek K, Thiede C, Marcucci G, Paschka P, Mayer RJ, Larson RA, Liu ET, Bloomfield CD (2008) Patients with acute myeloid leukemia and RAS mutations benefit most from postremission high dose cytarabine: a Cancer and Leukemia Group B study. Journal of clinical oncology. 26(28):4603-4609. https://doi.org/1 $0.1200 / J C O .2007 .14 .0418$

40. Schmid D, Heinze G, Linnerth B, Tisljar K, Kusec R, Geissler K, Sillaber C, Laczika K, Mitterbauer M, Zöchbauer S, Mannhalter C, Haas OA, Lechner K, Jäger U, Gaiger A (1997) Prognostic significance of WT1 gene expression at diagnosis in adult de novo acute myeloid leukemia. Leukemia. 11(5):639643. https://doi.org/10.1038/s.leu.2400620

41. Van Rhenen A, Moshaver B, Kelder A, Feller N, Nieuwint AW, Zweegman S et al (2007) Aberrant marker expression patterns on the CD34+ CD38- stem cell compartment in acute myeloid leukemia allows to distinguish the malignant from the normal stem cell compartment both at diagnosis and in remission. Leukemia. 21(8):1700-1707. https://doi.org/10.1038/sj.leu.2404754 
42. Majeti R (2011 Mar) Monoclonal antibody therapy directed against human acute myeloid leukemia stem cells. Oncogene. 30(9):1009-1019. https://doi. org/10.1038/onc.2010.511

43. Bakker $A B$, van den Oudenrijn $\mathrm{S}$, Bakker AQ, Feller N, van Meijer M, Bia JA et al (2004) C-type lectin-like molecule-1: a novel myeloid cell surface marker associated with acute myeloid leukemia. Cancer research. 64(22): 8443-8450. https://doi.org/10.1158/0008-5472.CAN-04-1659

44. Eissa DS, Kandeel EZ, Ghareeb M (2017) Human myeloid inhibitory C-lectin: a highly specific and stable acute myeloid leukemia marker. Hematological oncology. 35(4):814-820. https://doi.org/10.1002/hon.2352

\section{Publisher's Note}

Springer Nature remains neutral with regard to jurisdictional claims in published maps and institutional affiliations.

\section{Submit your manuscript to a SpringerOpen ${ }^{\circ}$ journal and benefit from:}

- Convenient online submission

- Rigorous peer review

- Open access: articles freely available online

- High visibility within the field

- Retaining the copyright to your article

Submit your next manuscript at $\boldsymbol{\sim}$ springeropen.com 